\title{
Bartholin's gland cyst presenting as anterior vaginal wall cyst: an unusual presentation
}

\author{
Supriya Dankher*, Vijay Zutshi, Sumitra Bachani, Renu Arora
}

Department of Obstetrics and Gynaecology, Vardhman Mahavir Medical College and Safdarjung Hospital, Delhi, India

Received: 30 June 2016

Accepted: 05 August 2016

\section{*Correspondence:}

Dr. Supriya Dankher,

E-mail: supsdhankher@gmail.com

Copyright: (c) the author(s), publisher and licensee Medip Academy. This is an open-access article distributed under the terms of the Creative Commons Attribution Non-Commercial License, which permits unrestricted non-commercial use, distribution, and reproduction in any medium, provided the original work is properly cited.

\begin{abstract}
The Bartholin's cyst can occur due to duct obstruction as a result of non-infectious occlusion of the ostium or from infection and edema compressing the duct. In this paper we are reporting a patient who presented to our hospital with something coming out through vagina. Her gynecological examination revealed, a $5 * 5 \mathrm{~cm}$ cystic, mobile, nontender mass arising completely from anterior vaginal wall with normal overlying vaginal mucosa. Intraoperatively, this cyst got ruptured, draining thick chocolate coloured material. Cyst wall was excised completely and sent for histopathology. To our surprise, histopathology reported this as Bartholin duct cyst. Literature search does not report any such case of Bartholin gland cyst.
\end{abstract}

Keywords: Bartholin's gland, Endometriosis, Mullerian cyst

\section{INTRODUCTION}

Bartholin gland is the major vestibular gland situated deeply within the posterior parts of the labia majora. The bartholin gland opens in the introitus with a duct of 1.5 to $2 \mathrm{~cm}$ length. Occlusion of the duct due to infection or non-infectious reasons can cause mucus accumulation and cyst formation. The prevalence of Bartholin cyst, is estimated approximately $2 \%{ }^{1}$

Bartholin's cyst generally presents as swelling or mass at vulva. Anterior vaginal wall cysts are by and large considered as remnants of mullerian duct and do not have haemorrhagic contents. Contrary to the usual presentation, Bartholin cyst in our case presented as anterior vaginal wall cyst. This type of presentation has not been reported earlier in literature.

\section{CASE REPORT}

A 30 year old woman, P3L3, reported to our gynaecological outpatient department with complaints of something coming out of vagina for last 1 year which had gradually increased in size. She had no associated pain, bowel or bladder dysfunction. Her gynecological examination revealed a $5 * 5 \mathrm{~cm}$ cystic, mobile, non-tender mass arising completely from anterior vaginal wall with normal overlying vaginal mucosa. Rest of her gynaecological examination was within normal limits. In pelvic ultrasonography, the uterus and adnexal structures were normal. Cystectomy was planned with a clinical preoperative diagnosis of anterior vaginal wall cyst. Intraoperatively, cyst got ruptured and dark chocolate brown colored thick fluid was drained (Figure 1). Cyst wall was in close proximity to bladder. Complete excision of cyst wall was done and sent for histopathological examination. 
On histopathological examination, multiple sections from cyst wall showed columnar to cuboidal epithelium with underlying fibro muscular tissue suggestive of Bartholin's cyst (Figure 2).

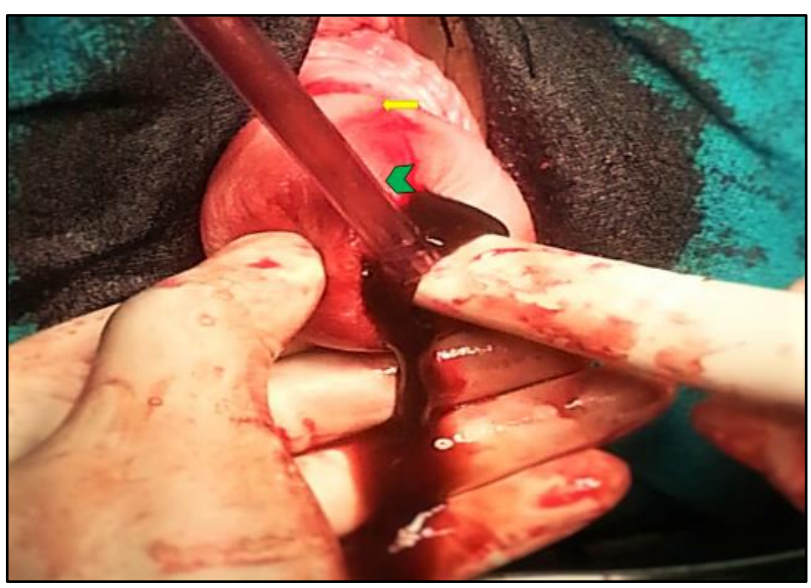

Figure 1: Peroperative picture showing anterior vaginal wall mucosa (yellow arrow), cyst wall (green arrowhead) and draining chocolate coloured contents.

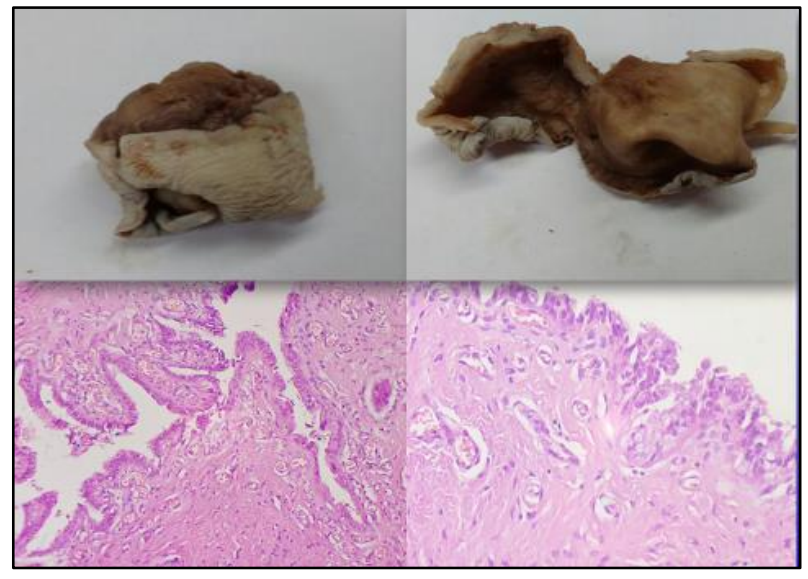

Figure 2: Gross and microscopic pictures of cyst during Histopathological examination

\section{DISCUSSION}

The Bartholin's glands are tubuloalveolar glands with acini composed of mucin secreting columnar, cuboidal, squamous or transitional columnar epithelium. ${ }^{1}$

Bartholin's cyst occurs due to obstruction of its duct. It typically presents with swelling at junction of upper two third and lower one third of labia majora but can extend anteriorly if it grows larger in size. ${ }^{2}$ Unusual presentation of Bartholin's cyst, as a painful firm necrotized mass on outer side of labia minora has also been reported. ${ }^{1}$ In our case, it presented as a cystic mass entirely in anterior vaginal wall mimicking as a benign anterior vaginal wall cyst and no such previously reported cases were found during our literature review.

Thick chocolate coloured contents gave a doubt of endometriotic cyst. Although, vaginal endo-metriosis is not so common. Generally, vaginal endometriotic lesions are seen in upper vagina, presenting as nodules. Gocmen et al, reported a case of endometriosis infiltrating the Bartholin gland with initial diagnosis of Bartholin gland cyst and clinical diagnosis of endometriosis was made during surgery when chocolate-colored fluid poured from cyst and was later on confirmed on histopathology. ${ }^{3}$ Endometriotic cyst clinically mimicking as Bartholin's cyst and urethral diverticulum had also been reported. ${ }^{4}$ Histopathology ruled out the possibility of endometriosis in the present case. Possible cause of haemorrhagic contents of cyst in our case could be coital trauma over a period of time.

\section{CONCLUSION}

Vaginal wall cysts are usually a remnant of mullerian duct. At times it is difficult to reach the base of cyst. There is a rare possibility of ureteral damage if one fails to recognize base properly. The authors suggest that it would be a good practice to locate the Bartholin duct opening before proceeding for dissection of doubtful cases. This one step can alleviate the apprehension of surgeon regarding ureteral damage which can rarely occur in mullerian duct cyst surgery, by locating ectopic Bartholin duct cyst. Even after that, vaginal cysts are difficult to distinguish clinically and histopathology remains the gold standard.

\section{Funding: No funding sources \\ Conflict of interest: None declared \\ Ethical approval: Not required}

\section{REFERENCES}

1. Soydinç HE, Sak ME, Evsen MS, Çaça FN. Heterotopically located Bartholin's Cyst. Eur J Gen Med. 2012;9(Suppl 1):36-8.

2. Rouzier R, Azarian M, Plantier F, Constancis E, Haddad B, Paniel BJ. Unusual presentation of Bartholin's gland duct cysts: anterior expansions. BJOG. 2005;112:1150-2.

3. Gocmen A, Inaloz HS, Sari I, Inaloz SS. Endometriosis in the Bartholin gland. Eur J Obstet Gynecol Reprod Biol. 2004;114(1):110-1.

4. Tiufekchieva E, Borisov S. Endometrial cysts of the vagina and the vulva (case reports and a literature review. Akush Ginekol (Sofiia). 2006;45(7):55-8.

Cite this article as: Dankher $\mathrm{S}$, Zutshi V, Bachani $\mathrm{S}$, Arora R. Bartholin's gland cyst presenting as anterior vaginal wall cyst: an unusual presentation. Int J Reprod Contracept Obstet Gynecol 2016;5:3216-7. 